\title{
Grid-Tie Rotating Solar Rooftop System Using Atmega
}

\author{
K.Ushanandhini ${ }^{\mathrm{a}, 1}$, A.Kiruthika ${ }^{\mathrm{a}}$, Dharmaprakash ${ }^{\mathrm{b}}$ \\ ${ }^{a} U G$ Student, Department of Electrical and Electronics Engineering, \\ ${ }^{b}$ Professor, Department of Electrical and Electronics Engineering, \\ Panimalar Institute of technology, Chennai, TN, India
}

\begin{abstract}
This paper presents a grid-tie rotating solar rooftop system solar power project which is powered by using Atmega 328 microcontroller. It includes solar panel, LCD display, and battery charging circuit and an inverter circuit with sun tracking capability. This project represents whether a particular industrial or residential load would be powered by the photovoltaic panel or the company. This project is based on Atmega 328 micro-controller which controls the solar array by rotating it consistently with the position of sun. This energy obtained from the solar array is then stored in battery which is then sent back to power the domestic or industrial area. The remaining energy is then reverted to the power house through the gird-tie system. Hence with the assistance of this project, power usage can be reduced by the renewable source of energy and profit can be earned with the help of the power which is fed back to the grid.
\end{abstract}

Keywords. Solar panel, Inverter, Atmega 328 Microcontroller, sun tracking capability, Grid-tie system, Profit

\section{Introduction}

Solar energy has been used for thousands of years in many different ways by people all over the world. This renewable energy source is cost free, non-polluting, greenhouse gases cannot be emitted while producing electricity and it is feasible, inexhaustible. However, with the efficient experimentation of scientists around the world, the solar energy is not efficiently or insufficiently used for the demand. According to recent survey of International Energy Agency, India will face the rising demand for energy over the next two decades, due to $25 \%$ of global growth, and is set to over lead the European Union by 2030. This project makes use of Atmega 328 microcontroller which controls the solar array by rotating it according to the position of sun. The sun tracking of the panel can be viewed through the LCD display and it automatically switches to the position in which maximum energy can be generated. The energy from the solar panel can be stored in battery or directed to the inverter which is then used to power the residential or industrial area. You can reduce energy costs, which will rise the value of your home or office and reduce toxic waste without losing the safety of the public power grid. The remaining energy is returned to the power station with the help of transformers through the grid-tie system [1][2]. Hence with the help of these system lots of power intake can be reduced.

\footnotetext{
${ }^{1}$ K.Ushanandhini, Department of Electrical and Electronics Engineering, Panimalar Institute of technology, Chennai; Email: ushanandhinius29@gmail.com.
} 


\section{Existing System}

An incorporation of solar power technologies into the existing energy structure depends on an in-depth understanding of the solar resource. The roof must be positioned so that it will be easier for the shingles to catch the sun. There must be sufficient area to put in solar shingles to gather enough light to supply electricity.

\section{Proposed System}

Our project presents a better and economical way to synchronize the solar panel output with the utility grid is shown in Figure 1. The Atmega 328 microcontroller was wellprogrammed such that the energy from the solar panel would provide electricity to the inverter circuit and also as it charges the battery circuit if needed.

The energy from the inverter circuit is then used to power loads as the primary source of electrical energy [1]. If the load acquainted excess energy either directly from the battery or inverter, available power is then fed back to the power station through the secondary transformer. Otherwise, if the electricity demand hang-back below the energy available by the solar panel, the microcontroller would cut the power line source [3].

As a result, an individual solar panel system owner can act as an electricity provider to the national power grid along with the residential grid. This method is usually carbon free or carbon neutral and intrinsically doesn't emit greenhouse gases during its operation.

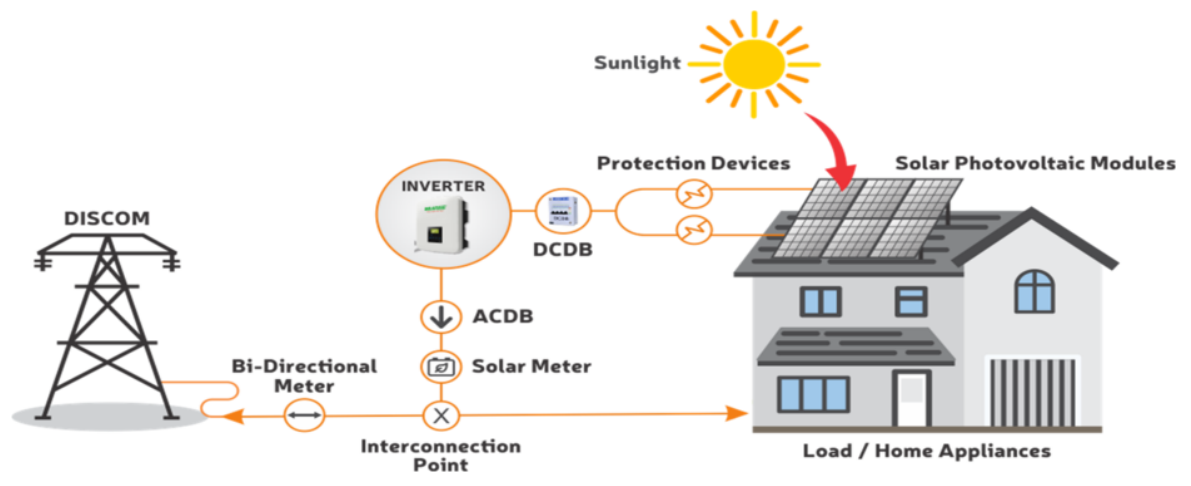

Figure 1. Proposed system

\section{Working}

It is an innovative system which can be used to store the abundant solar energy into a battery following in which excess energy can be returned to the power station using grid-tie. The population growth has led to increase in demands of people by both commercial as well as residential. The exhaustible resources are getting used-up at a rapid rate if this trend continuous we may face the energy crisis in future. In order to address this issue, our system comes to use [6-7].

The system begins by monitoring solar energy at different positions. It identifies the position with maximum power and reaches that position. 
There are three modes of operation

- Battery charging mode

- Load mode

- $\quad$ Grid mode

The system is powered using Atmega 328 microcontroller. It includes a solar panel and LCD display, battery charging circuit and an inverter circuit. Initially, the system monitors the solar power at different positions and angles and it automatically reaches the position with maximum incident solar energy. The outputs are shown in figure 2 , If the inverter is off, the system is in battery charging mode. The energy from the solar panel used to charge the battery [2]. If the inverter is ON, now the load mode is ON. The energy accumulated in the battery is converted into AC power, which is used to run AC load.

In Grid-mode, if the load gets turned OFF, all the excess energy is reverted to the power station with the help of grid-tie system. The system monitors power supplied to the grid and simultaneously keep running the total energy returned to the grid [4-5].
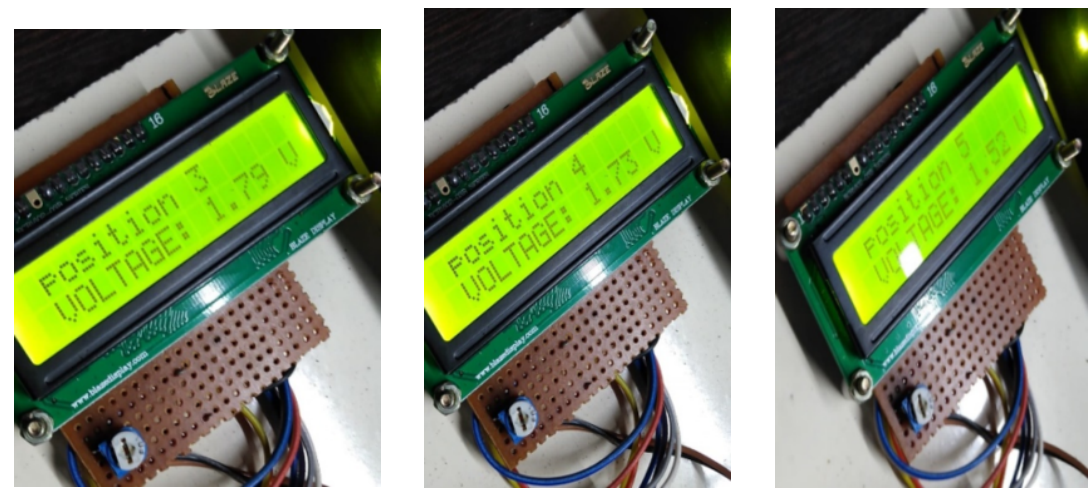

Figure 2. Load display of charging

\subsection{Battery charging mode}

The Figures 3 and 4 depicts the prototype model built. In battery charging mode, a 12V battery is mutually coupled with the transformer and an inverter. And an inverter is connected with the load, which comes under load mode [1-2].

As mentioned above, the electricity is generated by solar panel connected with a transformer which is then passed to inverter that converts the DC power to AC power, then fed through the MOSFET and IC drives, for the internal operation of Atmega 328 [2-4].

Without inverter operation, the energy available on the panel on the roof becomes unused. So, the role of inverter becomes predominant. The operation of battery and inverter system doesn't require the electrical grid to remain active, and that is the main advantage of off-grid residential and industrial installations [3]. 


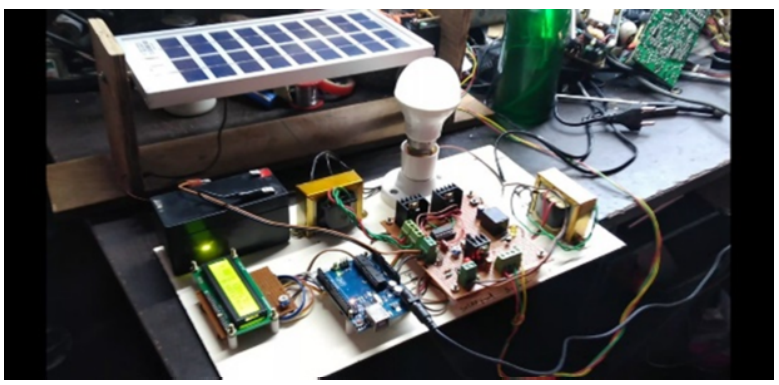

Figure 3. Prototype Model

\subsection{Grid mode}

In an AC coupled system, the grid-tied inverter is paired to the transformer, load and the battery bank [5]. The off-grid inverter provides a alternate source, which effectively tricks the grid-tied inverter into staying online. This enables you to charge your batteries and run essential appliances during an influence outage [3]

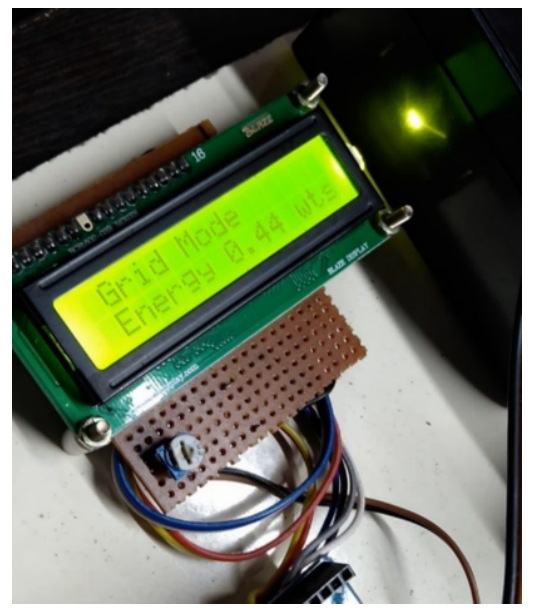

Figure 4. Grid mode

\section{Illustrations}

Figure 5 shows the inverter circuit and Figure 6 shows the overall circuit diagram.

\section{Conclusion}

The presented paper represents a photovoltaic system to produce electricity to domestic applications to reduce the over-reliance on the power generating company, which would reduce the energy costs. The given model includes PV solar array system with sun tracking capability, battery storage, a DC to AC inverter and an Atmega 328 microcontroller, which determines whether a certain residential load would be powered by the solar panel or the power generating company. This project monitors the power supplied to the grid and simultaneously keep running the total energy returned to the grid. It is an innovative system which can be used to store the abundant solar energy 


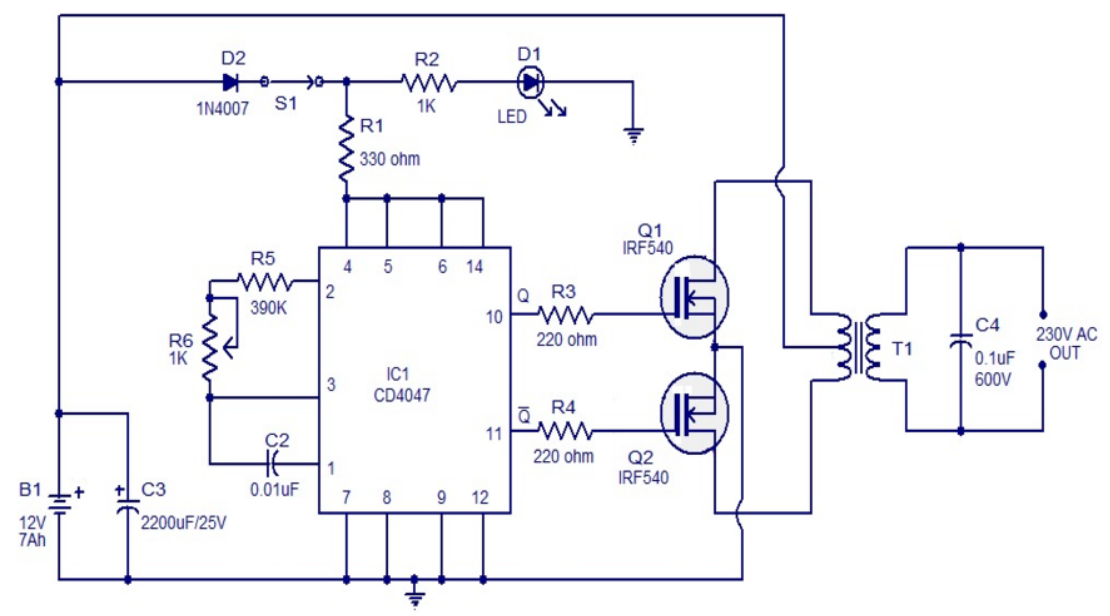

Figure 5 Inverter circuit

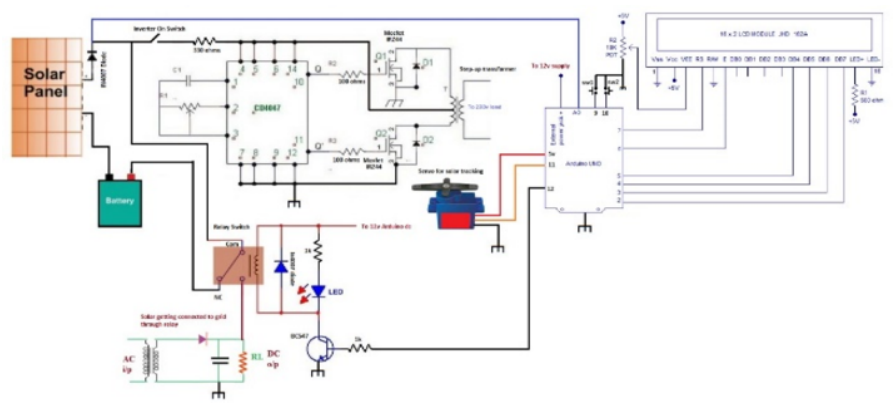

Figure 6 .Overall circuit diagram

into a battery following in which excess energy can be returned to the power station using grid-tie. This system may be executed in real residential applications too. However, both the photovoltaic system and Atmega 328 microcontroller have to be modified to fit the targeted applications fulfilling the power demand.

\section{References}

[1] Pearce, J. M. (2002). Photovoltaics - A path to sustainable futures. Futures, 34(7), 663-674. https://doi.org/10.1016/S0016-3287(02)00008-3

[2] Jahn, U., \& Nasse, W. (2004). Operational performance of grid-connected PV systems on buildings in Germany. Progress in Photovoltaics: Research and Applications, 12(6), 441-448. https://doi.org/ $10.1002 /$ pip. 550

[3] Denholm, P., Margolis, R., \& National Renewable Energy Laboratory. (2008). Supply Curves for Rooftop Solar PV-Generated Electricity for the United States. National Renewable Energy Laboratory, (November), 1-23. Retrieved from papers://a0cac570-6072-44e1-9d44-cdd15f758707/Paper/p2083

[4] Mackamul, K. and Wieting, R. The Shell Solar $245 \mathrm{~kW}$ Grid-Connected CIS Thin Film PV Rooftop Array: System Design and First Year Performance, Proceedings of the 19th European PVSEC, 2004, pp. 3084-3086.

[5] Payne, A., Duke, R., \& Williams, R. H. (2001). Accelerating residential PV expansion: Supply analysis for competitive electricity markets. Energy Policy, 29(10), 787-800. https://doi.org/10.1016/S03014215(01)00014-3

[6] Ganesh Babu R., Karunakaran A., Manikandan G., Kalimuthu Kumar S., Selvameena R. (2021) IoT in Smart Automation and Robotics with Streaming Analytical Challenges. In: Singh K.K., Nayyar A., 
Tanwar S., Abouhawwash M. (eds) Emergence of Cyber Physical System and IoT in Smart Automation and Robotics. Advances in Science, Technology \& Innovation (IEREK Interdisciplinary Series for Sustainable Development). Springer, Cham. https://doi.org/10.1007/978-3-030-66222-6_7

[7] R. G. Babu, V. V. Nathan, J. Bino, C. Amali and S. Ganesh, "IoT Security Enhancement with Automated Identification Device using IOT SENTINEL," 2021 11th International Conference on Cloud Computing, Data Science \& Engineering (Confluence), 2021, pp. 518-523, https://doi.org/ 10.1109/Confluence51648.2021.9377165 